\title{
Carboplatin treatment of antiestrogen-resistant breast cancer cells
}

\author{
MATHILDE S. LARSEN ${ }^{1,2}$, CHRISTINA W. YDE ${ }^{1}$, IB J. CHRISTENSEN ${ }^{3}$ and ANNE E. LYKKESFELDT ${ }^{1}$ \\ ${ }^{1}$ Breast Cancer Group, Unit of Cell Death and Metabolism, Danish Cancer Society Research Center, \\ DK-2100 Copenhagen $\emptyset ;{ }^{2}$ Department of Pathology, Herlev Hospital, DK-2730 Herlev; \\ ${ }^{3}$ Finsen Laboratory, Rigshospitalet, DK-2200 Copenhagen, Denmark
}

Received May 31, 2012; Accepted July 13, 2012

DOI: 10.3892/ijo.2012.1623

\begin{abstract}
Antiestrogen resistance is a major clinical problem in current breast cancer treatment. Therefore, biomarkers and new treatment options for antiestrogen-resistant breast cancer are needed. In this study, we investigated whether antiestrogen-resistant breast cancer cell lines have increased sensitivity to carboplatin, as it was previously shown with cisplatin, and whether low Bcl-2 expression levels have a potential value as marker for increased carboplatin sensitivity. Breast cancer cells resistant to the pure antiestrogen fulvestrant, and two out of four cell lines resistant to the antiestrogen tamoxifen, were more sensitive to carboplatin treatment compared to the parental MCF-7 cell line. This indicates that carboplatin may be an advantageous treatment in antiestrogen-resistant breast cancer; however, a marker for increased sensitivity would be needed. Low Bcl-2 expression was correlated with increased carboplatin response in the tamoxifen-resistant cell line MCF-7/TAM ${ }^{\mathrm{R}}-1$ and overexpression of Bcl-2 in this cell line resulted in significantly reduced carboplatin sensitivity, confirming the anti-apoptotic role of Bcl-2. However, neither Bcl-2 expression alone, nor Bcl-2 in combination with Bcl-xL and Bax, could explain the observed responses to carboplatin in all tamoxifen-resistant cell lines, indicating that more markers are needed to predict the response to carboplatin in tamoxifen-resistant breast cancer.
\end{abstract}

\section{Introduction}

Tamoxifen is the drug most widely used for breast cancer treatment. It is used both as adjuvant treatment and in the treatment of recurrent disease in estrogen receptor (ER)-positive breast cancer. Unfortunately, almost all patients treated for advanced disease will eventually develop resistance to treatment (1).

Correspondence to: Dr Christina W. Yde, Breast Cancer Group, Unit of Cell Death and Metabolism, Danish Cancer Society Research Center, Strandboulevarden 49, DK-2100 Copenhagen $\varnothing$, Denmark E-mail: cwy@cancer.dk

Key words: breast cancer, carboplatin, MCF-7, antiestrogen resistance
However, several patients will respond to second- and third-line endocrine therapy. Fulvestrant is a pure antiestrogen which is approved as second-line endocrine therapy for advanced breast cancer in postmenopausal women whose disease have progressed or relapsed on prior antiestrogen therapy (2), but development of resistance will inevitably occur. An alternative treatment option is therefore needed for these patients.

Cisplatin and carboplatin are effective chemotherapeutic drugs widely used in the treatment of solid tumors, such as testicular, ovarian, cervix, lung, head and neck, esophagus and bladder cancer (3). Cisplatin and carboplatin have been investigated as monotherapies and in combinations with other chemotherapeutic drugs and with trastuzumab in metastatic breast cancer (4). The efficacy of the platinum compounds depends upon which agents they are combined with and whether the patients have been previously treated with chemotherapy. The results of three review studies on platinum compounds in the treatment of advanced breast cancer are controversial. One review including only studies comparing regimens with platinum compounds to regimens without platinum compounds showed no benefit for the use of platinum (5). Another study concludes that cisplatin and carboplatin appeared to have efficacy in combination with specific chemotherapeutic agents (6). Likewise, Decatris et al conclude that platinum-monotherapy and platinum-containing combination regimens are effective in the treatment of metastatic breast cancer (7). Furthermore, preclinical studies have demonstrated a synergistic interaction between trastuzumab and cisplatin $(8,9)$. The combination of trastuzumab and cisplatin was effective in extensively pretreated metastatic breast cancer patients (10), and patients treated with a combination of adjuvant carboplatin, docetaxel and trastuzumab had an overall survival equal to patients treated with adjuvant cyclophosphamide, docetaxel and trastuzumab with lower risk of cardiotoxicity and leukaemia (11).

Since the platinum compounds are potential candidates for the treatment of metastatic breast cancer, the efficacy of cisplatin in antiestrogen-resistant breast cancer cell lines were tested in a previous work from our laboratory (12). A tamoxifen-resistant cell line and a panel of six fulvestrant-resistant cell lines were more sensitive to cisplatin-induced cell death compared to the parental, ER-positive and antiestrogen-sensitive MCF-7 cell line, indicating a benefit of using cisplatin in the treatment of endocrine-resistant breast cancer. 
However, cisplatin has severe side effects such as nefro-, neuro- and ototoxicity as well as major emetic side effect. The platinum analogue carboplatin with significantly less renal-, neuro- and ototoxicity and less severe nausea and vomiting is a useful alternative to cisplatin (3). The major cytotoxic target of cisplatin and carboplatin is DNA. Their interaction with DNA leads to DNA adduct formation, primarily intrastrand crosslink adducts, which induce apoptosis. Thus, the platinum agents kill cells by triggering their apoptosis program, and downregulation of the apoptotic signal is an essential characteristic associated with cisplatin resistance (13).

The Bcl-2 family of proteins is regulators of apoptosis consisting of both anti-apoptotic cell survival proteins (i.e. Bcl-2 and Bcl-xL) and pro-apoptotic cell death proteins (i.e. Bax). The family members form homo- and heterodimers with each other and the interaction among the different proteins controls the propensity of a cell to undergo apoptosis (14). Yde et al found that downregulation of Bcl-2 in MCF-7 cells sensitized the cells to cisplatin treatment (15). This was followed by a study of fulvestrant-resistant cell lines and one tamoxifen-resistant cell line $\left(\mathrm{MCF}-7 / \mathrm{TAM}^{\mathrm{R}}-1\right)$ where a decreased level of Bcl-2 in the resistant cell lines compared to MCF-7, was concurrent with the finding of increased sensitivity to cisplatin in the resistant cell lines (12). We have previously found that fulvestrant-resistant cell lines express less Bcl-2 than the parental, antiestrogen sensitive MCF-7 cell line (16). Bcl-2 is upregulated by estrogenmediated activation of ER in MCF-7 breast cancer cells (17), and the decreased expression of ER in our antiestrogen-resistant cell model (18-20) may explain the decreased expression of Bcl-2.

The anti-apoptotic effect of Bcl-2 makes it an obvious candidate as a predictive marker of response to chemotherapy. A recent review evaluated the literature on 18 genes associated with clinical chemosensitivity, and among these, Bcl-2 overexpression was found to be associated with resistance to first-line chemotherapy (21).

The aim of this study was to explore if antiestrogen-resistant cell lines have increased sensitivity to carboplatin similarly to that previously shown with cisplatin. Moreover, we exploited the role of $\mathrm{Bcl}-2$ on the effect of carboplatin treatment in tamoxifen-resistant breast cancer, and we investigated if expression of Bcl-2, Bcl-xL and Bax proteins was associated with carboplatin sensitivity.

\section{Materials and methods}

Cell cultures. The MCF-7 cell line was originally obtained from the Human Cell Culture Bank, Mason Research Institute (Rockville, MD, USA) and adapted to grow in low serum concentration (1\%) to reduce the estrogens supplied through the serum to a level resembling the concentration of circulating estradiol in postmenopausal women (22). The cells were maintained in growth medium [Dulbecco's modified Eagle's medium (DMEM/F12)] without phenol red (Gibco/Invitrogen, CA, USA), supplemented with $1 \%$ heat-inactivated fetal calf serum (FCS) (Gibco), $2 \mathrm{mM}$ glutamax (Gibco) and $6 \mathrm{ng} / \mathrm{ml}$ insulin (Sigma-Aldrich, St. Louis, MO, USA). Tamoxifen-resistant cell lines, MCF-7/TAM ${ }^{\mathrm{R}}-1$ ( TAM $\left.^{\mathrm{R}}-1\right), \mathrm{MCF}^{-7 / \mathrm{TAM}^{\mathrm{R}}-4}$ $\left(\mathrm{TAM}^{\mathrm{R}}\right.$-4), MCF-7/TAM ${ }^{\mathrm{R}}-7$ (TAM ${ }^{\mathrm{R}}$-7) and MCF-7/TAM ${ }^{\mathrm{R}}-8$ $\left(\mathrm{TAM}^{\mathrm{R}}-8\right)$ were established from MCF-7 cells as previously described $(18,20,23)$. The fulvestrant-resistant cell line
MCF-7/182 ${ }^{\mathrm{R}}-6\left(182^{\mathrm{R}}-6\right)$ was established as described (19) and was maintained in growth medium supplemented with $0.1 \mu \mathrm{M}$ ICI 182,780 (fulvestrant) (Tocris Cookson, Bristol, UK), while the tamoxifen-resistant cell lines $\mathrm{TAM}^{\mathrm{R}}-1, \mathrm{TAM}^{\mathrm{R}}-4, \mathrm{TAM}^{\mathrm{R}}-7$ and $\mathrm{TAM}^{\mathrm{R}}-8$ were maintained in growth medium supplemented with $1 \mu \mathrm{M}$ tamoxifen (Sigma-Aldrich). For experiments, $25 \mathrm{U} / \mathrm{ml}$ penicillin and $25 \mu \mathrm{g} / \mathrm{ml}$ streptomycin (Gibco) were added to the growth medium. All cell lines were maintained at $37^{\circ} \mathrm{C}$ in humidified air containing $5 \% \mathrm{CO}_{2}$.

Treatments and determination of cell number and cell death. All cell lines were seeded in 24-well plates $\left(2 \mathrm{~cm}^{2}\right.$ wells) in growth medium 2 days before treatment. At the onset of treatment, growth medium was changed to medium containing 50, $100,200,300$ or $400 \mu \mathrm{M}$ carboplatin (Sigma-Aldrich). After $48 \mathrm{~h}$ treatment, cell number was determined by a crystal violet colorimetric assay as described previously (24). For each cell line at least four independent dose response growth experiments with carboplatin were done. Each concentration was tested in quadruplicate.

For cell death determination, MCF-7 and $182^{\mathrm{R}}-6$ cells treated for 24 and $48 \mathrm{~h}$ with carboplatin were incubated for $15 \mathrm{~min}$ with $0.5 \mu \mathrm{M}$ SYTOX-Green nucleic acid stain (Invitrogen), harvested by trypsination, and combined with floating cells from the medium. Cells were sedimented by centrifugation and resuspended in phosphate-buffered saline (PBS) containing $1 \%$ FCS. The fraction of SYTOX-Green-positive cells (representing dead cells as SYTOX-Green stains the nucleic acids in cells with disrupted plasma membrane) was measured using a FACSCalibur (Becton Dickinson) flow cytometer. Cells $(10,000)$ were analyzed using the FL-1 filter for determination of the fraction of SYTOX-positive cells. The data were analyzed using the Cell Quest Pro software.

Western blot analysis. All cell lines were cultured in T25 flasks (Nunc, Roskilde, Denmark) until 70-80\% confluent. For analyses of ER $\alpha, \mathrm{Bcl}-2$, Bax and Bcl-xL, antiestrogen-resistant cell lines were grown in standard medium containing the respective antiestrogen. Medium was renewed every second or third day. After 6-7 days, the cells were washed with PBS and harvested in radioimmunoprecipitation (RIPA) buffer $(100 \mathrm{mM} \mathrm{NaCl}$, $20 \mathrm{mM}$ Tris- $\mathrm{HCl}, 1 \%$ Triton $\mathrm{X}-100,0.5 \%$ sodium-deoxycholate, $0.1 \%$ SDS and $1 \mathrm{mM}$ EDTA, with the addition of $1 \mathrm{mM}$ DTT, $1 \mathrm{mM} \mathrm{NaF}, 10 \mathrm{mM} \beta$-glycerolphosphate, $100 \mu \mathrm{M} \mathrm{Na}_{3} \mathrm{VO}_{4}$, $150 \mu \mathrm{M}$ PMSF, and one tablet/10 ml complete mini protease inhibitor cocktail (Roche, Hvidovre, Denmark)). Determination of protein concentration was done using the Bio-Rad protein assay kit (Bio-Rad Laboratories, Munich, Germany) with bovine serum albumin as standard. Proteins were separated by $15 \%$ or $4-15 \%$ SDS-PAGE gels and transferred to an Immobilon-P membrane (Millipore, Bedford, MA, USA) by semi-dry electroblotting. Membranes were blocked with Tris-buffered saline (TBS) containing 5\% nonfat dry-milk, 5\% FCS and 0.2\% Tween-20 (Merck, Hohenbrunn, Germany). Immunostaining was performed with primary antibodies directed against ER $\alpha$ (SP1, 1:5,000, Thermo Fisher Scientific, Fremont, CA, USA), Bcl-2 (clone 124, 1:2,000, Dako, Glostrup, Denmark), Bcl-xL (54H6, 1:1,000, Cell Signaling Technology, Beverly, MA, USA), Bax (2772, 1:1,000, Cell Signaling Technology) and $\beta$-actin (AC-15, 1:100,000, Sigma-Aldrich). Secondary goat anti-rabbit and 
rabbit anti-mouse horseradish peroxidase-conjugated antibodies (P0448 and P0260 respectively; 1:2,000, Dako) were used. The ECL Plus Western Blotting Detection System (Amersham, GE Healthcare, Buckinghamshire, UK) was used for visualization of the proteins according to the manufacturer's instructions. Western blot analyses were repeated at least three times on independent cell lysates with reproducible results.

Transfections. Bcl-2 overexpressing MCF-7/TAM ${ }^{\mathrm{R}}-1$ cell lines were established by transfection of cells with pCEP4-BCL-2 (kindly provided by Dr Marja Jaättelä, Danish Cancer Society, Copenhagen, Denmark). Control cells were transfected with pCEP4 (empty vector). Transfection was performed using a Nucleofector electroporation system (Amaxa Biosystems, Cologne, Germany). Stable Bcl-2 expressing cell clones were selected and maintained in growth medium containing $50 \mu \mathrm{g} / \mathrm{ml}$ hygromycin $\mathrm{B}$ and $1 \mu \mathrm{M}$ tamoxifen.

Statistics. For all cell growth assays at least four independent experiments with quadruplicate measures were performed and the data pooled for statistical analysis. OD-measurements from crystal violet staining were converted to a rate of the respective untreated control and evaluated on the log scale. The assumptions of normally distributed data on the log scale were assessed using residuals and variance homogeneity was tested using Levine's test. Analysis was done using mixed modeling where treatment and cell line were regarded as fixed variables and the individual experiments were regarded as random effects in the model.

The back transformed estimates based on the mixed model are plotted as Forest Plots, illustrating the ratios between number of resistant cells and number of the control cells, at each concentration. A ratio equal to 1.0 means that the two cell lines were equally reduced compared to their control. Less than 1.0 means that the resistant cell line was reduced more than MCF-7, analogous to increased sensitivity to carboplatin. The $95 \%$ confidence intervals for the estimate are also plotted, showing the precision of the results. Growth experiments with the fulvestrant-resistant cell line $182^{\mathrm{R}}-6$ and the transfected cell lines are illustrated as cell number in $\%$ of the untreated control from a representative experiment. For all experiments, results were considered significant at $\mathrm{P}<0.05$. Calculations were performed using SAS, version 9.2 (SAS Institute, Cary, NC, USA).

\section{Results}

Fulvestrant-resistant cells were more sensitive to carboplatin than parental MCF-7 cells. The fulvestrant-resistant cell line $182^{\mathrm{R}}-6$, which had earlier been shown to have increased sensitivity towards cisplatin-induced cell killing compared to MCF-7, was chosen for the experiments to test if fulvestrant-resistant cells were also more sensitive than MCF-7 to carboplatin. Doseresponse experiments were performed after $48 \mathrm{~h}$ treatment with carboplatin. The response was expressed as percent of the cell number in the untreated control. The result from a representative experiment with quadruplicate samples at each tested carboplatin concentration is shown in Fig. 1A. At 200, 300 and $400 \mu \mathrm{M}$ carboplatin, $182^{\mathrm{R}}-6$ cells were statistically significantly more sensitive than MCF-7 cells. Fig. 1B shows a Forest plot with pooled data from four experiments, each with quadrupli-
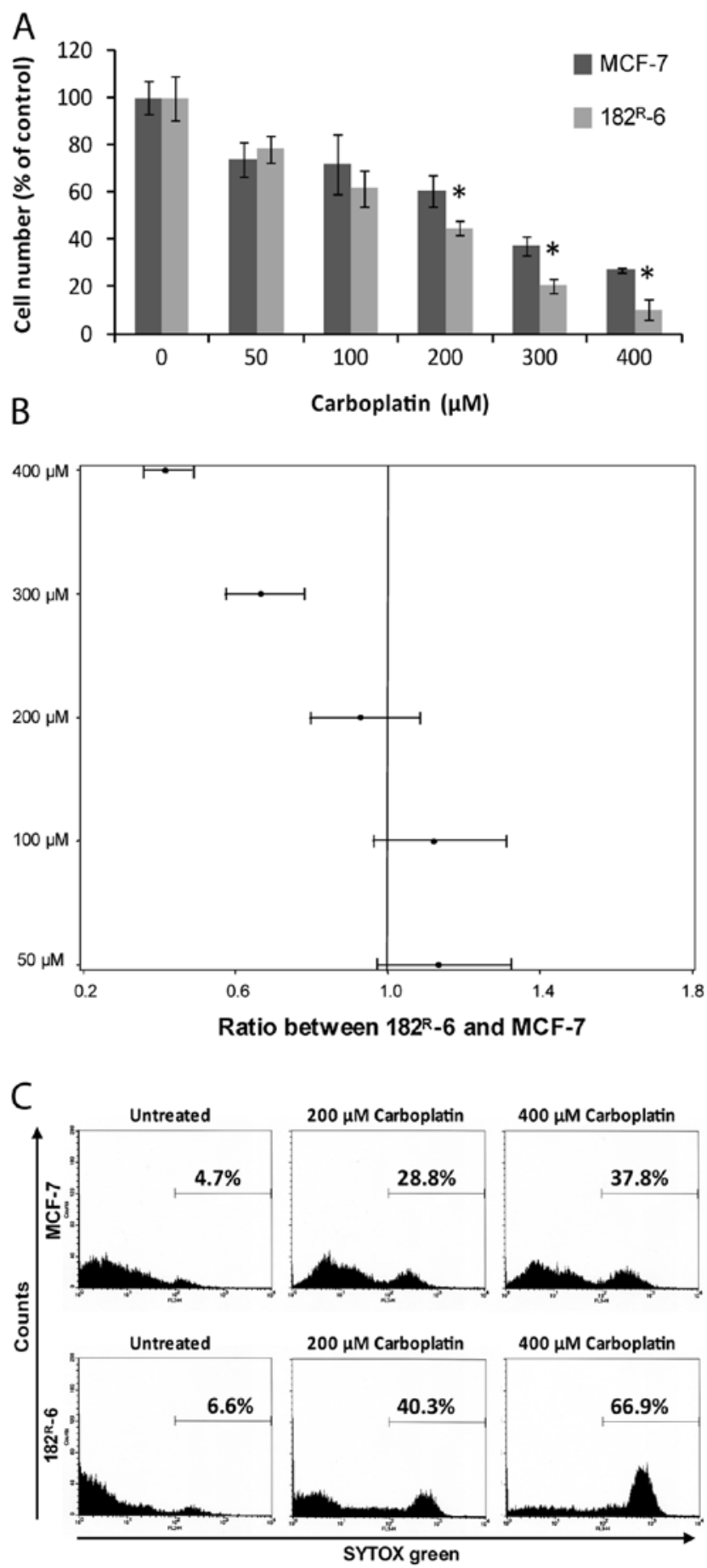

Figure 1. Effect of carboplatin on cell number and cell death in MCF-7 and fulvestrant-resistant $182^{\mathrm{R}}-6$ cells. Cells were treated with the indicated concentrations of carboplatin for $48 \mathrm{~h}$. (A) Cell number was determined by a crystal violet staining method and presented as percentage of untreated cells. Four independent dose response experiments were performed and cell numbers in a representative experiment are presented. Asterisk denotes statistically significant difference from MCF-7 cells and bars indicate standard error of mean of quadruplicate samples. (B) Forest plot illustrating the ratios between cell number in $182^{\mathrm{R}}-6$ and MCF-7 cells after $48 \mathrm{~h}$ treatment with carboplatin at the indicated concentrations. Data from four individual experiments were pooled for statistical analysis. Bars indicate $95 \%$ CI-limits of the estimated ratios. (C) Cell death fractions were determined by SYTOX-Green staining and flow cytometry. Fluorescence intensity was determined in 10,000 MCF-7 and $182^{\mathrm{R}}-6$ cells from untreated cultures and from cultures treated with carboplatin. The peaks corresponding to the dead cells are indicated in the figure and mean values of percent dead cells from four independent experiments are shown. 

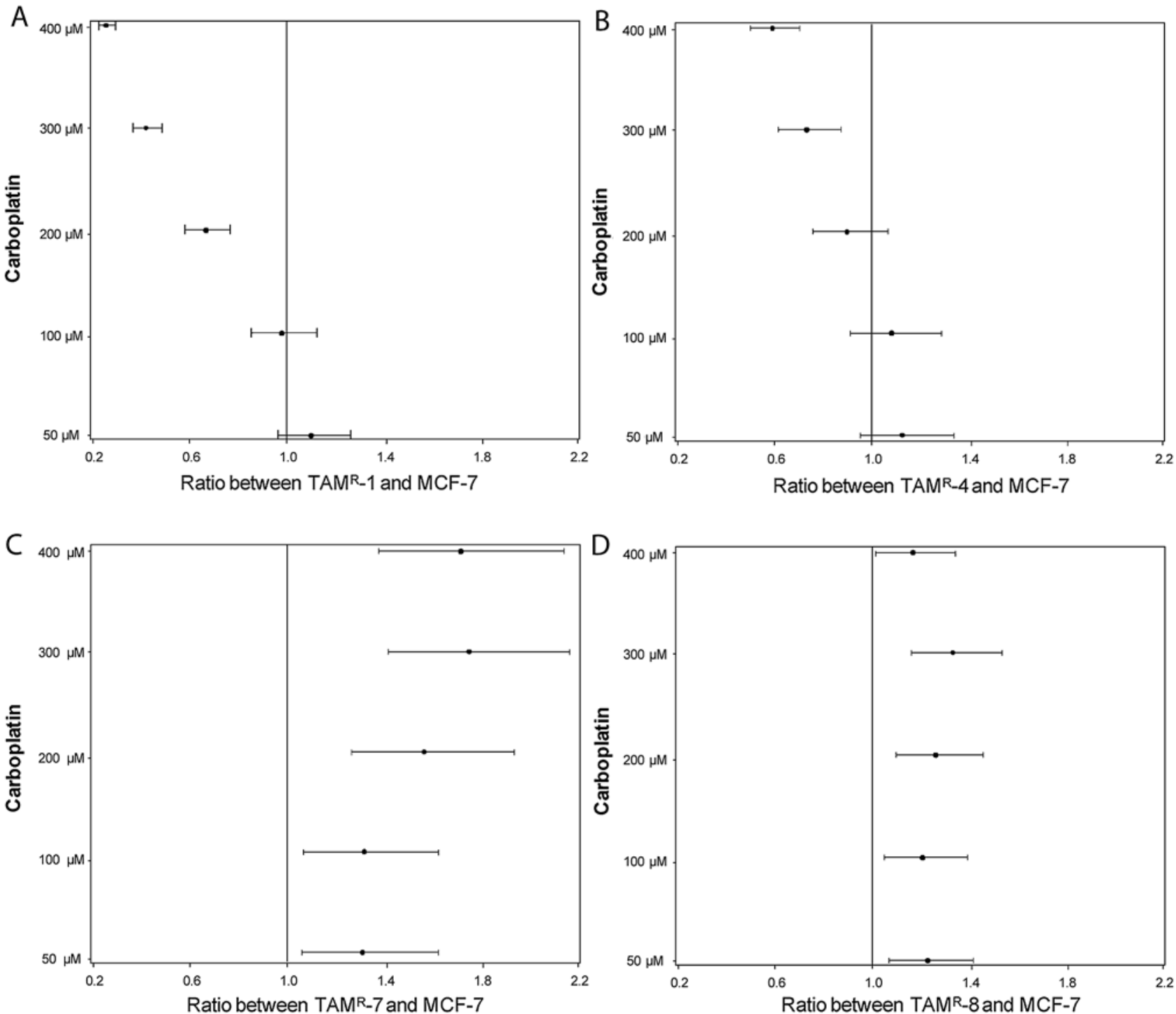

Figure 2. Forest plots illustrating the ratio between cell number in tamoxifen-resistant cells and MCF-7 cells after $48 \mathrm{~h}$ treatment with carboplatin at the indicated concentrations. (A) TAM ${ }^{\mathrm{R}}-1$ versus MCF-7, (B) TAM ${ }^{\mathrm{R}}-4$ versus MCF-7, (C) TAM ${ }^{\mathrm{R}}-7$ versus MCF-7, (D) TAM ${ }^{\mathrm{R}}-8$ versus MCF-7. The experiments were performed as described in the legend of Fig. 1. Data from four individual experiments with MCF-7 and resistant cell lines were pooled for statistical analysis. Bars, 95\% CI-limits of the estimated ratios.

cate samples of the tested carboplatin concentrations. The ratios between cell number of $182^{\mathrm{R}}-6$ and MCF-7 at different concentrations of carboplatin are shown. This illustrates that $182^{\mathrm{R}}-6$ cells were significantly more sensitive towards carboplatin at concentrations of $300 \mu \mathrm{M}$ and $400 \mu \mathrm{M}$ with a ratio between $182^{\mathrm{R}}-6$ and MCF-7 of 0.67 (95\% CI: 0.57-0.78) and 0.42 (95\% CI: 0.36-0.49), respectively.

Cell death determinations were performed to disclose whether the effect of carboplatin was a cytotoxic effect leading to cell death as previously shown for cisplatin (12). Fig. 1C shows the fraction of dead cells in untreated MCF-7 and $182^{\mathrm{R}}-6$ cultures and in cultures treated for $48 \mathrm{~h}$ with $200 \mu \mathrm{M}$ and $400 \mu \mathrm{M}$ carboplatin, respectively. The fraction of dead cells is low in untreated cultures. Carboplatin kills both MCF-7 and $182^{\mathrm{R}}-6$ cells, but at $400 \mu \mathrm{M}$ concentration, $182^{\mathrm{R}}-6$ cells are much more sensitive to carboplatin-mediated cell killing than MCF-7 cells. The death fractions indicated in the figure are average values from three independent experiments.
Two out of four tamoxifen-resistant cell lines were more sensitive to carboplatin. Tamoxifen is a drug that is used far more often than fulvestrant and we therefore explored the relevance of carboplatin treatment in a model system of tamoxifen-resistant cell lines, established by long-term treatment of MCF-7 with tamoxifen. Tamoxifen-resistant cell lines and MCF-7 cells were treated with carboplatin in doses of 50, 100, 200, 300 and $400 \mu \mathrm{M}$ for $48 \mathrm{~h}$ and cell numbers were determined. All cell lines, including MCF-7, responded to carboplatin with a decrease in the cell number. The ratios between the cell number of the TAM ${ }^{\mathrm{R}}-1$ and MCF-7 are shown in Fig. 2A, TAM ${ }^{\mathrm{R}}-4$ and MCF-7 in Fig. 2B, TAM ${ }^{\mathrm{R}}-7$ and MCF-7 in Fig. 2C and TAM $^{\mathrm{R}}-8$ and MCF-7 in Fig. 2D. Two of the four resistant cell lines $\left(\mathrm{TAM}^{\mathrm{R}}-1\right.$ and $\left.\mathrm{TAM}^{\mathrm{R}}-4\right)$ were significantly more sensitive towards carboplatin than MCF-7 at 200, 300 and $400 \mu \mathrm{M}$ (except at $200 \mu \mathrm{M}$ in the case of $\mathrm{TAM}^{\mathrm{R}}-4$ ). The other two cell lines, $\mathrm{TAM}^{\mathrm{R}}-7$ and $\mathrm{TAM}^{\mathrm{R}}-8$, were less sensitive at all concentrations of carboplatin, compared to MCF-7 cells. 
A
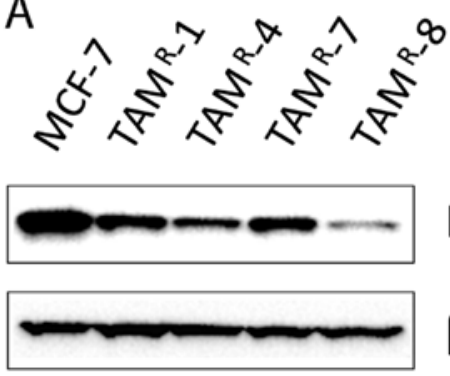

ER

$\beta$-actin

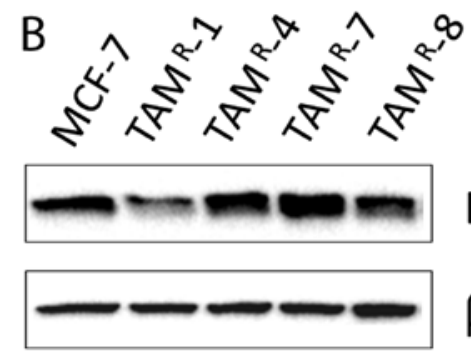

$\mathrm{Bcl}-2$

$\beta$-actin

Figure 3. Expression of (A) ER and (B) Bcl-2 in MCF-7 and tamoxifen-resistant cell lines. Western blot analyses were performed with cell lysates from MCF-7 and tamoxifen resistant cell lines grown in their standard medium. Loading control was $\beta$-actin. Three independent experiments were performed and representative blots are shown.

$B c l-2$ expression is not associated with the growth response to carboplatin treatment. Yde et al found in the fulvestrant-resistant cell lines that the low level of Bcl-2 expression can at least partly explain the increased sensitivity towards cisplatin (12). Previous studies have found low ER level in $\mathrm{TAM}^{\mathrm{R}}-1$ and the fulvestrant-resistant cell lines $(18,19)$. Low Bcl-2 level is expected as a consequence of the low ER level. Therefore, Western blot analyses were performed for detection of ER and $\mathrm{Bcl}-2$ protein levels (Fig. 3), and it was found that all tamoxifen-resistant cell lines had reduced levels of ER compared to MCF-7 (Fig. 3A). The expression of Bcl-2 was lower in $\mathrm{TAM}^{\mathrm{R}}-1$ and $\mathrm{TAM}^{\mathrm{R}}-8$ compared to MCF-7 cells, whereas Bcl-2 levels in TAM ${ }^{\mathrm{R}}-4$ and $\mathrm{TAM}^{\mathrm{R}}-7$ were similar to MCF-7 (Fig. 3B). Thus, $\mathrm{TAM}^{\mathrm{R}}-1$ was the only cell line in which increased sensitivity towards carboplatin was associated with low level of Bcl-2. Noteworthy, the level of $\mathrm{Bcl}-2$ was low in $\mathrm{TAM}^{\mathrm{R}}-8$ which had a reduced carboplatin sensitivity; and the level of Bcl-2 was similar in $\mathrm{TAM}^{\mathrm{R}}-4$, $\mathrm{TAM}^{\mathrm{R}}-7$ and MCF-7, contrary to expectation, since TAM ${ }^{\mathrm{R}}-4$ was more sensitive and TAM ${ }^{\mathrm{R}}-7$ less sensitive than MCF-7.

Resistant cells with stable overexpression of Bcl-2 have decreased sensitivity towards carboplatin. Since $\mathrm{TAM}^{\mathrm{R}}-1$ was the only tamoxifen-resistant cell line in which reduced sensitivity to carboplatin treatment was associated with reduced Bcl-2 expression, we investigated whether stable overexpression of Bcl-2 protein by transfection of the Bcl-2 gene could reduce the effect of carboplatin. We used a plasmid without the Bcl-2 insert (empty vector) as a control. Expression of the Bcl-2 constructs in $\mathrm{TAM}^{\mathrm{R}}-1$ was verified by western blot analysis (Fig. 4A). TAM ${ }^{\mathrm{R}}-1$ cells transfected with the empty vector $\left(\mathrm{TAM}^{\mathrm{R}}-1 / \mathrm{EV}\right)$ had a Bcl-2 expression, which was similar to the $\mathrm{Bcl}-2$ expression in $\mathrm{TAM}^{\mathrm{R}}-1$; both of them were
A
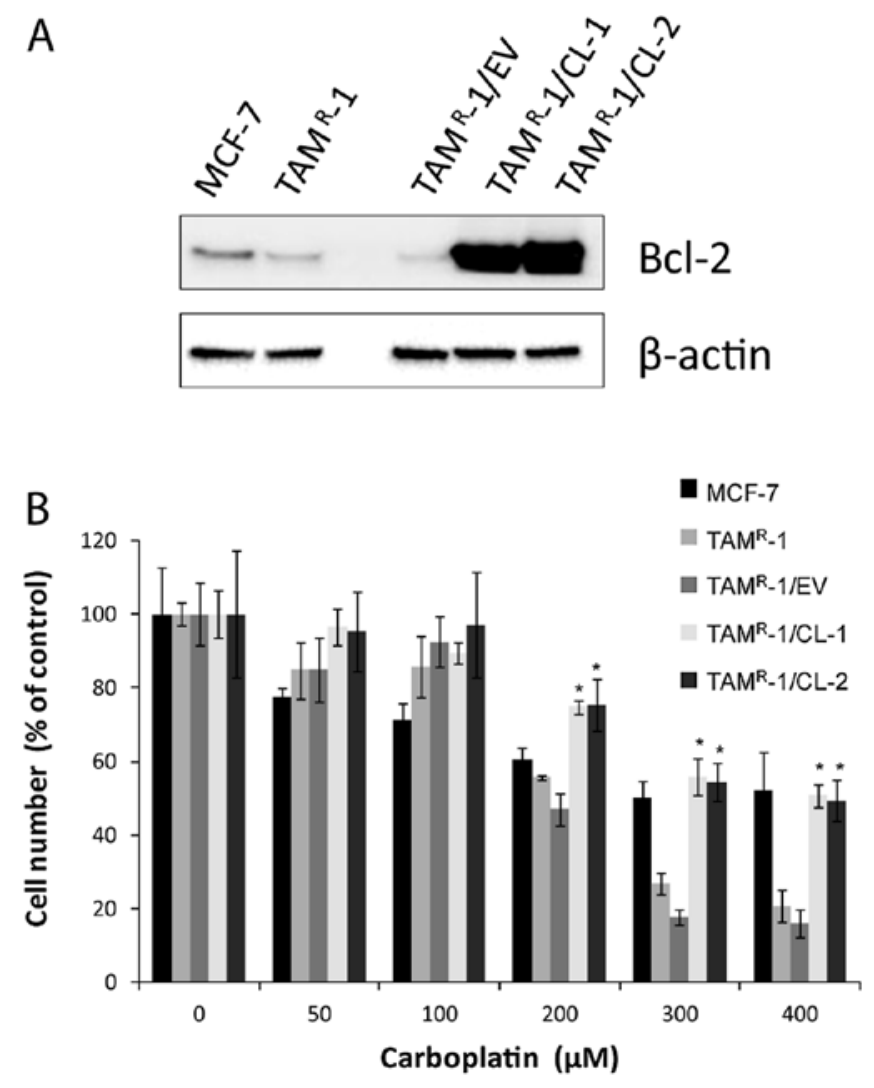

Figure 4. Bcl-2 overexpressing $\mathrm{TAM}^{\mathrm{R}}-1$ cells and response to carboplatin treatment. (A) Western blot analysis showing Bcl-2 level in MCF-7, TAM ${ }^{\mathrm{R}}-1$, and in $\mathrm{TAM}^{\mathrm{R}}-1$ cells with the vector control $\mathrm{TAM}^{\mathrm{R}}-1 / \mathrm{EV}$, or ectopic expression of a functional Bcl-2 construct; TAM ${ }^{\mathrm{R}}-1 / \mathrm{CL}-1$ and $\mathrm{TAM}^{\mathrm{R}}-1 / \mathrm{CL}-2$. Loading control was $\beta$-actin. (B) Dose-response growth experiment with carboplatin in MCF-7, $\mathrm{TAM}^{\mathrm{R}}-1, \mathrm{TAM}^{\mathrm{R}}-1 / \mathrm{EV}, \mathrm{TAM}^{\mathrm{R}}-1 / \mathrm{CL}-1$ and $\mathrm{TAM}^{\mathrm{R}}-1 / \mathrm{CL}-2$. The cells were treated with the indicated concentrations of carboplatin for $48 \mathrm{~h}$. Cell number was determined by a crystal violet staining method and presented as per cent of the respective untreated cell line. Asterisk denotes statistically significant difference between $\mathrm{TAM}^{\mathrm{R}}-1 / \mathrm{EV}$ and the clones with ectopic $\mathrm{Bcl}-2$ expression; TAM ${ }^{\mathrm{R}}-1 / \mathrm{CL}-1$ and $\mathrm{TAM}^{\mathrm{R}}-1 / \mathrm{CL}-2$, respectively. Bars indicate standard deviation of quadruplicate samples. Three experiments with similar results were performed and a representative experiment is presented.

low compared to MCF-7 as expected. The two independently established clones, $\mathrm{TAM}^{\mathrm{R}}-1 / \mathrm{Bcl}-2 /$ clonel (CL-1) and $\mathrm{TAM}^{\mathrm{R}}-1 /$ Bcl-2/clone2 (CL-2) with a high, stable expression of Bcl-2, were tested for sensitivity to carboplatin treatment. The two clones were significantly less sensitive than the empty vector and $\mathrm{TAM}^{\mathrm{R}}-1$ at concentrations of $200-400 \mu \mathrm{M}$ carboplatin, Fig. 4B.

$B c l-x L$ and Bax did not give supplementary information on the sensitivity of the cell lines. To see if other proteins from the Bcl-2 family might explain the differences in carboplatin sensitivity, we investigated the level of two other proteins from the Bcl-2 family: the anti-apoptotic Bcl-xL and the pro-apoptotic Bax proteins. As seen in Fig. 5A, the level of Bcl-xL was similar in MCF-7, TAM ${ }^{\mathrm{R}}-1, \mathrm{TAM}^{\mathrm{R}}-4$, and $\mathrm{TAM}^{\mathrm{R}}-7$. Only $\mathrm{TAM}^{\mathrm{R}}-8$ had an increased level of Bcl-xL compared to MCF-7. The level of Bax was increased in $\mathrm{TAM}^{\mathrm{R}}-1$ and decreased in $\mathrm{TAM}^{\mathrm{R}}-8$ compared to MCF-7 whereas TAM ${ }^{\mathrm{R}}-4$ and $\mathrm{TAM}^{\mathrm{R}}-7$ displayed similar level as MCF-7 cells, Fig. 5B. 
A
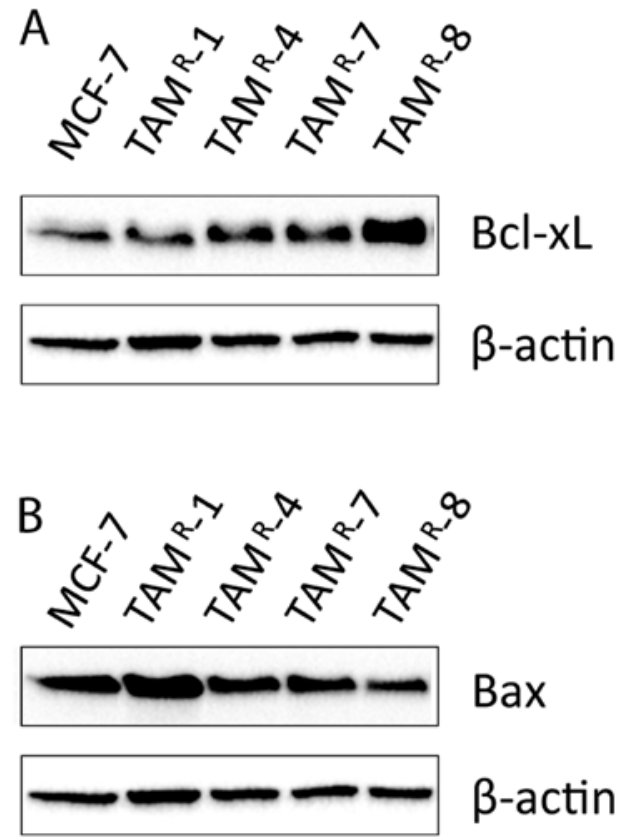

Figure 5. Expression of (A) Bcl-xL and (B) Bax in MCF-7 and tamoxifenresistant cell lines. Western blot analyses were performed with cell lysates from MCF-7 and tamoxifen-resistant cell lines grown in their standard medium. Loading control was $\beta$-actin. Three independent experiments were performed and representative blots are shown.

\section{Discussion}

Based on previous results showing increased sensitivity to cisplatin in the tamoxifen-resistant cell line, $\mathrm{TAM}^{\mathrm{R}}-1$, and a panel of fulvestrant-resistant cell lines (12), we investigated whether antiestrogen-resistant cell lines have increased sensitivity to carboplatin. Furthermore, based on the extensive use of tamoxifen as first-line endocrine therapy for premenopausal breast cancer patients and also for many postmenopausal breast cancer patients, we wanted to test a panel of tamoxifen-resistant cell lines for response to carboplatin treatment to unravel whether it is a general phenomenon that both fulvestrant- and tamoxifen-resistant cell lines are sensitized to treatment with platinum compounds.

We found that carboplatin, a drug with less severe side effects than cisplatin, had the same advantage as cisplatin in exerting more severe cytotoxic effect on the fulvestrant-resistant $182^{\mathrm{R}}-6$ cell line than MCF-7 cells. Regarding the effect of carboplatin in tamoxifen-resistant cell lines, two out of four cell lines were more sensitive to carboplatin compared to MCF-7, whereas the other two were less sensitive.

A possible explanation for the increased sensitivity of the fulvestrant-resistant cell lines is a lower expression level of the anti-apototic Bcl-2 protein due to the lower level of ER in fulvestrant-resistant cells compared to MCF-7. Therefore, the ER level was determined in the tamoxifen-resistant cell lines and all four cell lines displayed reduced ER level compared to MCF-7. In contrast to fulvestrant-resistant cell lines, only two of the four tamoxifen-resistant cell lines expressed reduced Bcl-2 level, and in only one cell line, $\mathrm{TAM}^{\mathrm{R}}-1$, the reduced $\mathrm{Bcl}-2$ level was associated with increased sensitivity to carboplatin treatment. We then tested the effect of $\mathrm{Bcl}-2$ overexpression in $\mathrm{TAM}^{\mathrm{R}}-1$ by transfection of a plasmid containing the Bcl-2 gene, and this confirmed that $\mathrm{Bcl}-2$ can protect $\mathrm{TAM}^{\mathrm{R}}-1$ cells from the toxic effect of carboplatin.

The finding that $\mathrm{TAM}^{\mathrm{R}}-8$ cells, which also had reduced Bcl-2 level, were less sensitive to carboplatin treatment than MCF-7 cells, clearly demonstrated that Bcl-2 is not the only factor influencing the response to carboplatin treatment. Therefore, Bcl-2 alone is not a suitable marker for evaluation of the effect of carboplatin. As Bcl-2 is a member of a large family of proteins regulating apoptosis, we explored the possibility that other members of the family could counterbalance the effect of the Bcl-2 level. We tested the association of sensitivity with two other apoptosis regulating proteins, the anti-apoptotic protein $\mathrm{Bcl}-\mathrm{xL}$ and the pro-apoptotic protein Bax. The Bcl-xL level was increased and Bax level was decreased in $\mathrm{TAM}^{\mathrm{R}}-8$ compared to $\mathrm{MCF}-7$. Considering that the $\mathrm{Bcl}-2$ level was not as severely decreased in $\mathrm{TAM}^{\mathrm{R}}-8$ as in $\mathrm{TAM}^{\mathrm{R}}-1$ cells, the increase in the anti-apoptotic Bcl-xL and the decrease in the pro-apoptotic Bax level may explain the reduced sensitivity in $\mathrm{TAM}^{\mathrm{R}}-8$ compared to MCF-7 cells. The level of Bax was increased in TAM ${ }^{\mathrm{R}}-1$, which fits with the increased sensitivity of these cells. However, in $\mathrm{TAM}^{\mathrm{R}}-4$ and $\mathrm{TAM}^{\mathrm{R}}-7$ cells, neither Bcl-xL nor Bax could explain the observed carboplatin sensitivity.

Altogether, the individual tamoxifen-resistant cell lines appear to be very different. Compared to the fulvestrant-resistant cell lines, all showing increased sensitivity to platinum treatment, the tamoxifen-resistant cell lines $\mathrm{TAM}^{\mathrm{R}}-1,4,7$ and 8 were very different concerning their sensitivity to carboplatin treatment and the expression of apoptosis-related proteins. This may reflect that many different mechanisms contribute to the occurrence of tamoxifen resistance, whereas fulvestrant resistance appears to occur from a shift from ER to HER signaling (25). In tamoxifenresistant cells, ER may still be functional and tamoxifen can even act as an agonist; while in fulvestrant-resistant cells, ER is completely blocked. Although the Bcl-2 level was reduced compared to MCF-7 in two tamoxifen-resistant cell lines, the Bcl-2 level was even lower in fulvestrant-resistant cells (16). This leaves the possibility that other apoptosis-related proteins could easily overrule the effect of Bcl-2 in the tamoxifen-resistant cells.

These data show that the determination of $\mathrm{Bcl}-2$ status alone is not sufficient in assessing the impact on apoptosis of the Bcl-2 death pathway; the assessment of levels of the other members of the Bcl-2 family may better determine the extent to which apoptosis may occur. A clinical study reported a correlation between reduced Bax and shorter overall survival, faster time to progression, and failure to respond to chemotherapy in patients with metastatic breast cancer (26). We found that Bax and Bcl-xL could not explain differences in carboplatin sensitivity of $\mathrm{TAM}^{\mathrm{R}}-4$ and $\mathrm{TAM}^{\mathrm{R}}-7$ compared to MCF-7, indicating that other pathways regulating apoptosis are more important. Although Bcl-2 was found to predict response to chemotherapy in some studies (21), contradictory results of no relationship between $\mathrm{Bcl}-2$ expression and clinical response to chemotherapy were reported by others (27). On the other hand, the latter study found mutated p53 to be a significant predictor of poor clinical response rate. This again points to the possibility that assessment of other apoptosis pathways are required to evaluate the propensity of a cell to undergo apoptosis as a response to chemotherapy. Apoptosis depends on the expression 
of a specific set of genes, among them are wild-type p53 that can induce apoptosis, and Akt that has anti-apoptotic activity. The wild-type p53 transcriptionally downregulates the expression of the $\mathrm{Bcl}-2$ gene and activates the expression of the Bax gene (28). In human breast carcinoma, an inverse correlation between p53 immunostaining, a surrogate end-marker of mutant $\mathrm{p} 53$ protein and $\mathrm{Bcl}-2$ expression has been reported (29). Akt has the ability to inactivate the pro-apoptotic factor Bad (30). A previous study from our laboratory with four fulvestrant-resistant cell lines and $\mathrm{TAM}^{\mathrm{R}}-1$ revealed a higher level of phosphorylated Akt in three of the fulvestrant-resistant cell lines and in TAM ${ }^{\mathrm{R}}-1$ (31). These are examples of possible contributors to a complex regulation of apoptosis related to the response to chemotherapy.

In conclusion, this study shows that carboplatin is more efficient for treatment of fulvestrant-resistant $182^{\mathrm{R}}-6$ cells than MCF-7 cells in agreement with the previous finding of increased sensitivity to cisplatin in fulvestrant-resistant cell lines (12). However, this did not apply to all tamoxifen-resistant cell lines, indicating that platinum compounds would be a candidate for treatment of breast cancer relapse after fulvestrant treatment but not necessarily after tamoxifen treatment.

Our previous study indicated that low Bcl-2 level is a potential predictive marker for sensitivity to cisplatin treatment (12). If carboplatin should be used in the treatment of breast cancer patients relapsing on tamoxifen treatment, a marker to predict the most sensitive tumors would be needed. Our study on four tamoxifen-resistant cell lines did not support the use of low Bcl-2 level as single marker for carboplatin response. Determination of the level of the anti-apoptotic Bcl-xL protein and the pro-apoptotic Bax protein was neither sufficient to explain the observed responses to carboplatin treatment, demonstrating that a complex network of factors is involved in the response of tamoxifen-resistant breast cancer cells to carboplatin treatment.

\section{Acknowledgements}

We thank Inger Heiberg for excellent technical assistance. The study was financially supported by Danish Cancer Society (grant no. DP08013) and Danish Agency for Science Technology and Innovation (grant no. 09-063068 and 09-063623).

\section{References}

1. Ali S and Coombes RC: Endocrine-responsive breast cancer and strategies for combating resistance. Nat Rev Cancer 2 : 101-112, 2002.

2. Howell A, DeFriend DJ, Robertson JF, Blamey RW, Anderson L, Anderson E, Sutcliffe FA and Walton P: Pharmacokinetics, pharmacological and anti-tumour effects of the specific antioestrogen ICI 182780 in women with advanced breast cancer. Br J Cancer 74: 300-308, 1996.

3. Go RS and Adjei AA: Review of the comparative pharmacology and clinical activity of cisplatin and carboplatin. J Clin Onco 17: 409-422, 1999.

4. Perez EA: Carboplatin in combination therapy for metastatic breast cancer. Oncologist 9: 518-527, 2004.

5. Carrick S, Ghersi D, Wilcken N and Simes J: Platinum containing regimens for metastatic breast cancer. Cochrane Database Syst Rev 3: CD003374, 2004.

6. Martin M: Platinum compounds in the treatment of advanced breast cancer. Clin Breast Cancer 2: 190-208, 2001.

7. Decatris MP, Sundar S and O'Byrne KJ: Platinum-based chemotherapy in metastatic breast cancer: current status. Cancer Treat Rev 30: 53-81, 2004.
8. Colbern GT, Hiller AJ, Musterer RS, Working PK and Henderson IC: Antitumor activity of Herceptin in combination with STEALTH liposomal cisplatin or nonliposomal cisplatin in a HER2 positive human breast cancer model. J Inorg Biochem 77: 117-120, 1999.

9. Pegram M, Hsu S, Lewis G, Pietras R, Beryt M, Sliwkowski M, Coombs D, Baly D, Kabbinavar F and Slamon D: Inhibitory effects of combinations of HER-2/neu antibody and chemotherapeutic agents used for treatment of human breast cancers Oncogene 18: 2241-2251, 1999.

10. Pegram MD, Lipton A, Hayes DF, Weber BL, Baselga JM, Tripathy D, Baly D, Baughman SA, Twaddell T, Glaspy JA and Slamon DJ: Phase II study of receptor-enhanced chemosensitivity using recombinant humanized anti-p185HER2/neu monoclonal antibody plus cisplatin in patients with HER2/neu-overexpressing metastatic breast cancer refractory to chemotherapy treatment. J Clin Oncol 16: 2659-2671, 1998.

11. Slamon D, Eiermann W, Robert N, Pienkowski T, Martin M, Press M, Mackey J, Glaspy J, Chan A, Pawlicki M, Pinter T, Valero V, Liu MC, Sauter G, von Minckwitz G, Visco F, Bee V, Buyse M, Bendahmane B, Tabah-Fisch I, Lindsay MA, Riva A and Crown J; Breast Cancer International Research Group: Adjuvant trastuzumab in HER2-positive breast cancer. N Engl J Med 365: 1273-1283, 2011.

12. Yde CW, Gyrd-Hansen M, Lykkesfeldt AE, Issinger OG and Stenvang J: Breast cancer cells with acquired antiestrogen resistance are sensitized to cisplatin-induced cell death. Mol Cancer Ther 6: 1869-1876, 2007.

13. Siddik ZH: Cisplatin: mode of cytotoxic action and molecular basis of resistance. Oncogene 22: 7265-7279, 2003.

14. Schorr K, Li M, Krajewski S, Reed JC and Furth PA: Bcl-2 gene family and related proteins in mammary gland involution and breast cancer. J Mammary Gland Biol Neoplasia 4: 153-164, 1999.

15. Yde CW and Issinger OG: Enhancing cisplatin sensitivity in MCF-7 human breast cancer cells by down-regulation of Bcl-2 and cyclin D1. Int J Oncol 29: 1397-1404, 2006.

16. Christensen GL, Jepsen JS, Fog CK, Christensen IJ and Lykkesfeldt AE: Sequential versus combined treatment of human breast cancer cells with antiestrogens and the vitamin D analogue EB1089 and evaluation of predictive markers for vitamin D treatment. Breast Cancer Res Treat 85: 53-63, 2004

17. Larsen SS, Heiberg I and Lykkesfeldt AE: Anti-oestrogen resistant human breast cancer cell lines are more sensitive towards treatment with the vitamin D analogue EB1089 than parent MCF-7 cells. Br J Cancer 84: 686-690, 2001.

18. Lykkesfeldt AE, Madsen MW and Briand P: Altered expression of estrogen-regulated genes in a tamoxifen-resistant and ICI 164,384 and ICI 182,780 sensitive human breast cancer cell line, MCF-7/TAM ${ }^{\mathrm{R}}$-1. Cancer Res 54: 1587-1595, 1994.

19. Lykkesfeldt AE, Larsen SS and Briand P: Human breast cancer cell lines resistant to pure anti-estrogens are sensitive to tamoxifen treatment. Int J Cancer 61: 529-534, 1995.

20. Madsen MW, Reiter BE, Larsen SS, Briand P and Lykkesfeldt AE: Estrogen receptor messenger RNA splice variants are not involved in antiestrogen resistance in sublines of MCF-7 human breast cancer cells. Cancer Res 57: 585-589, 1997.

21. Sekine I, Shimizu C, Nishio K, Saijo N and Tamura T: A literature review of molecular markers predictive of clinical response to cytotoxic chemotherapy in patients with breast cancer. Int J Clin Oncol 14: 112-119, 2009.

22. Lykkesfeldt AE and Sorensen EK: Effect of estrogen and antiestrogens on cell proliferation and synthesis of secreted proteins in the human breast cancer cell line MCF-7 and a tamoxifen resistant variant subline, AL-1. Acta Oncol 31: 131-138, 1992.

23. Lykkesfeldt AE and Briand P: Indirect mechanism of oestradiol stimulation of cell proliferation of human breast cancer cell lines. Br J Cancer 53: 29-35, 1986.

24. Lundholt BK, Briand P and Lykkesfeldt AE: Growth inhibition and growth stimulation by estradiol of estrogen receptor transfected human breast epithelial cell lines involve different pathways. Breast Cancer Res Treat 67: 199-214, 2001.

25. Frogne T, Benjaminsen RV, Sonne-Hansen K, Sorensen BS, Nexo E, Laenkholm AV, Rasmussen LM, Riese DJ II, de Cremoux P, Stenvang P and Lykkesfeldt AE: Activation of ErbB3, EGFR and Erk is essential for growth of human breast cancer cell lines with acquired resistance to fulvestrant. Breast Cancer Res Treat 114: 263-275, 2009. 
26. Krajewski S, Blomqvist C, Franssila K, Krajewska M Wasenius VM, Niskanen E, Nordling S and Reed JC: Reduced expression of proapoptotic gene BAX is associated with poor response rates to combination chemotherapy and shorter survival in women with metastatic breast adenocarcinoma. Cancer Res 55: 4471-4478, 1995.

27. Bottini A, Berruti A, Bersiga A, Brizzi MP, Brunelli A, Gorzegno G, DiMarco B, Aguggini S, Bolsi G, Cirillo F, Filippini L, Betri E, Bertoli G, Alquati P and Dogliotti L: p53 but not bcl-2 immunostaining is predictive of poor clinical complete response to primary chemotherapy in breast cancer patients. Clin Cancer Res 6: 2751-2758, 2000.

28. Miyashita T, Krajewski S, Krajewska M, Wang HG, Lin HK, Liebermann DA, Hoffman B and Reed JC: Tumor suppressor p53 is a regulator of bcl-2 and bax gene expression in vitro and in vivo. Oncogene 9: 1799-1805, 1994.
29. Silvestrini R, Veneroni S, Daidone MG, Benini E, Boracchi $P$ Mezzetti M, Di Fronzo G, Rilke F and Veronesi U: The Bcl-2 protein: a prognostic indicator strongly related to $\mathrm{p} 53$ protein in lymph node-negative breast cancer patients. J Natl Cancer Inst 86: 499-504, 1994.

30. Benbrook DM, Masamha CP: The pro-survival function of Akt kinase can be overridden or altered to contribute to induction of apoptosis. Curr Cancer Drug Targets 11: 586-599, 2011.

31. Frogne T, Jepsen JS, Larsen SS, Fog CK, Brockdorff BL and Lykkesfeldt AE: Antiestrogen-resistant human breast cancer cells require activated protein kinase B/Akt for growth. Endocr Relat Cancer 12: 599-614, 2005. 